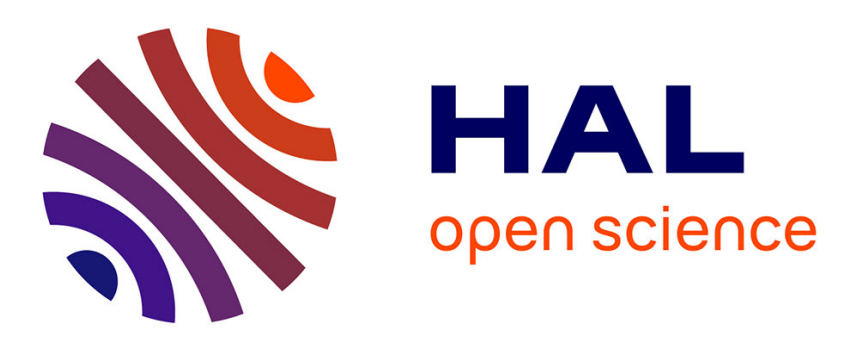

\title{
Nano crystalline diamond MicroWave Chemical Vapor Deposition growth on three dimension structured silicon substrates at low temperature
}

O. Antonin, R. Schoeppner, M. Gabureac, L. Pethö, J. Michler, Patrice Raynaud, T. Nelis

\section{To cite this version:}

O. Antonin, R. Schoeppner, M. Gabureac, L. Pethö, J. Michler, et al.. Nano crystalline diamond MicroWave Chemical Vapor Deposition growth on three dimension structured silicon substrates at low temperature. Diamond and Related Materials, 2018, 83, pp.67-74. 10.1016/j.diamond.2018.01.007 . hal-02322185

\section{HAL Id: hal-02322185 \\ https://hal.science/hal-02322185}

Submitted on 25 Jan 2021

HAL is a multi-disciplinary open access archive for the deposit and dissemination of scientific research documents, whether they are published or not. The documents may come from teaching and research institutions in France or abroad, or from public or private research centers.
L'archive ouverte pluridisciplinaire HAL, est destinée au dépôt et à la diffusion de documents scientifiques de niveau recherche, publiés ou non, émanant des établissements d'enseignement et de recherche français ou étrangers, des laboratoires publics ou privés. 


\title{
Nano crystalline diamond MicroWave Chemical Vapor Deposition growth on three dimension structured silicon substrate at low temperature
}

\author{
O. Antonin ${ }^{*}, 1,2, \$$, R. Schoeppner ${ }^{3, \$}$, M. Gabureac ${ }^{1}$, L. Pethö 3 , \\ J. Michler ${ }^{3}$, P. Raynaud ${ }^{2}$ and T. Nelis ${ }^{* *}, 1,3$
}

\author{
${ }^{1}$ Institute of Applied Laser, Photonics and Surface Technologies, Bern University of Applied Sciences, Quellgasse 21, 2501 Biel, \\ Switzerland \\ ${ }^{2}$ LAboratoire PLAsma et Conversion de l'Energie, LAPLACE, Université de Toulouse, CNRS, INPT, UPS, 118 route de Narbonne, \\ 31062 Toulouse Cedex 9, France \\ ${ }^{3}$ Empa, Swiss Federal Laboratories for Materials Science and Technology, Laboratory for Mechanics of Materials and Nanostructures, \\ Feuerwerkerstrasse 39, 3602 Thun, Switzerland \\ $\S$ : Both authors contributed equally to this work.
}

Keywords: CVD, MW-LPCVD, MEPS, Diamond, Nano Crystalline Diamond, 3D step coverage

\begin{abstract}
Nano crystalline diamond (NCD) films grown at a temperature below $400{ }^{\circ} \mathrm{C}$ can open new applications on temperature sensitive substrates such as polymers or low-melting point alloys. One requirement for the applicative use of NCD is the ability of depositing on structured substrate showing high aspect ratio. This work presents a study of the 3D conformity NCD deposition at low temperature $\left(350^{\circ} \mathrm{C}\right)$ and low pressure $(30 \mathrm{~Pa})$. Silicon wafers have been structured using a mask-less DRIE process and seeded with nano-diamond particles. The NCD films were grown on these 3D patterned Si substrate with various trench geometries to provide means of determining the limiting geometries of this technique. By measuring the step coverage with changing trench width, a threshold for conformal NCD growth can be determined. The NCD films at the bottom of the $100 \mu \mathrm{m}$ deep trenches were continuous down to an aspect ratio of 1:7.
\end{abstract}

\section{Introduction}

The unparalleled hardness, low friction and heat conductivity properties of diamond make it attractive for many applications. The use of diamond as a coating has increased with the development of high growth-rate protocols using Hot Filament Chemical Vapor Deposition (HF-CVD), which usually operates at high substrate temperatures around 600 to $900{ }^{\circ} \mathrm{C}$ [1]. However, the high substrate temperatures (> $600^{\circ} \mathrm{C}$ ) of HF-CVD limits the possible substrate materials.

Developments over the past few years in the area of MicroWave Plasma Enhanced CVD (MW-PE-CVD) have made the deposition of CVD diamond possible at far lower substrate temperatures $\left(<400{ }^{\circ} \mathrm{C}\right)[2-4]$. These developments have mainly focused on the deposition of Poly- Crystalline Diamond (PCD) and Nano-Crystalline diamond (NCD). In contrast to PCD, NCD has low surface roughness, while keeping similar mechanical properties [5]. Films with these properties have strong application interests [6] as protective layers for cutting tools, Micro- Electro-Mechanical System (MEMS) devices [7], thermal conductive

layers for high power devices, and coatings for Atomic Force Microscope (AFM) tips [8-11]. Different approaches have been developed to achieve large area deposition of NCD at low temperatures. The linear array configuration has been successful in depositing NCD at low temperatures on large substrate areas $[2,3,12,13]$. This process makes use of the surface-wave, i.e. propagation of the microwave at the interface between the plasma and a dielectric. A different approach using an array of coaxial plasma sources has been used to achieve NCD deposition at low temperatures and on large surface areas [14]. In both approaches, the possibility of producing large area treatment is somewhat compromised by the need for complex power distributors and impedance matching systems. Application of the NCD deposition methods to industrial application requires deposition on structured substrates, with high aspect ratio features to determine the process's limitations. In addition, threedimensional patterned substrates are a useful tool for the study and modelling of CVD growth [15-17], which is still not fully understood. Floter et al. [18] in 1995, reported a strong dependence of the nucleation density on the orientation of the surface when bias pre-treatment of structured Si substrate was employed. This lead to a very low or absent diamond growth on the side-wall of trenches. However, the bottom of trenches were coated with diamond for aspect ratios reaching 7 , with a maximum film thickness related to the width of the trench, rather than its depth or the length of the treatment. In this study, the MW-CVD deposition was performed at elevated temperatures $\left(750{ }^{\circ} \mathrm{C}-900{ }^{\circ} \mathrm{C}\right)$ and a pressure of $4000 \mathrm{~Pa}$. Monteiro and Liu [19] reported in 2003 on the effect of a diamond like carbon pre-treatment on diamond growth on structured surfaces. They achieved homogeneous growth on

\footnotetext{
* Corresponding author: olivier.antonin@bfh.ch, Phone: +413232162 89

** thomas.nelis@bfh.ch, Phone: +41323216320
} 
structures showing an aspect ratio below one. The exact deposition conditions were not reported in this work, but from the crystalline structure it can be concluded that the substrate temperature was above $500{ }^{\circ} \mathrm{C}$. Ralchenko et al. reported in 2004 [20], again in the context of large diamond crystal growth, that seeding with diamond particles in an ultra-sonic bath treatment yielded best results in 3D conformity of the pre-treatment. Eaton et al. reported in 2001 [9] on modelling the effect of oxygen on the capability of conformal 3D diamond deposition. Due to the higher lifetime of $\mathrm{OH}$ radicals, compared to atomic hydrogen, they predict better step coverage when oxygen is added to the gas mixture. However, even if interesting information can be found in these publications, none of them explicitly addresses the lowtemperature deposition of NCD on structured surfaces. In this publication, we present work using a set of Hi-Wave sources in a Matrix Elementary Plasma Source configuration (MEPS) [21] for NCD deposition using low power density (< $\left.7.6 \mathrm{Wcm}^{-2}\right)$, low deposition temperature $\left(350{ }^{\circ} \mathrm{C}\right)$ and low pressure of $30 \mathrm{~Pa}$. The structure of the deposited NCD film was evaluated on a structured three dimension (3D) silicon substrate with trenches up to $100 \mu \mathrm{m}$ deep with aspect ratios ranging from 1:1 to $1: 7$.

\section{Experimental details}

\subsection{Substrate preparation}

A $100 \mathrm{~mm}$ diameter single crystal silicon wafer with $\langle 100\rangle$ orientation and $525 \mu \mathrm{m}$ thickness was micro patterned in a cleanroom environment. The surface was first coated with the AZ 9221 photoresist from Microchemicals to a thickness of 2 $\mu \mathrm{m}$ by spinning at $4200 \mathrm{RPM}$, then soft baking at $110^{\circ} \mathrm{C}$. This photoresist enables high resolution, straight sidewalls and good resistance to the subsequent deep reactive ion etch process, without the need for a post-development hard bake step. The resist layer was exposed by direct laser writing in a Heidelberg MLA150 with a beam diameter of $1 \mu \mathrm{m}$ and an exposure intensity of $130 \mathrm{~mJ} / \mathrm{cm} 2$. The exposed photoresist is removed by immersion into Microchemicals AZ400K developer, then the substrate is rinsed with DI water. To transfer the pattern into the silicon substrate, an Alcatel AMS 200E inductively coupled Radio Frequency (RF) plasma etcher was used to run a Bosch process with the inductively coupled plasma (ICP) power set to $1800 \mathrm{~W}$. In each cycle, the substrate was exposed to the silicon etchant $\left(\mathrm{SF}_{6}\right)$ for $6 \mathrm{~s}$, then to the sidewall passivation gas $\left(\mathrm{C}_{4} \mathrm{~F}_{8}\right)$ for $2 \mathrm{~s}$. This two-stage process was repeated until the target depth of $100 \mu \mathrm{m}$ was achieved. The average etch rate was $4.88 \mu \mathrm{m} / \mathrm{s}$. The remaining photoresist was removed using a barrel plasma etcher with $400 \mathrm{ml} / \mathrm{min} \mathrm{O}_{2}$ flow and a 500W RF plasma. The silicon wafer was diced into $10 \times 10 \mathrm{~mm}$ chips along the crystalline axes with a Disco DAD321 automated dicing saw. All substrates were seeded by NeoCoat $\mathrm{SA}, \mathrm{CH}$, using a proprietary process by immersing in a bath containing diamond nanoparticles (around $10 \mathrm{~nm}$ in diameter) in suspension. This seeding process usually yields a high density of nuclei [14]. Prior to deposition, all samples were exposed to pure $\mathrm{H}_{2}$ plasma with increasing microwave power for approximately $1 \mathrm{~h}$.

\subsection{NCD Deposition}

The MEPS reactor used for the diamond deposition was home-built [21]. It employs seven microwaves antennas (HiWave, SAIREM, FR) [22], arranged in a hexagonal configuration with a distance of $55 \mathrm{~mm}$ between sources. Each of the sources is individually connected via a coaxial cable to a $200 \mathrm{~W}$ solid-state microwave generator. Each of the seven microwave generators can independently frequency tuned to reduce the reflected power below $5 \mathrm{~W}$. The reactor concept resembles in many points the Distributed Antenna Array (DAA) $[4,14,23]$. The major differences are the use of solidstate generators and auto matched microwave antennas, allowing for operation without power distributors and additional impedance matching. A more detailed description of the Hi-Wave antennas used in this work is given in [24] The gas supply system consists of four mass flow controllers and an Edwards E2M40 rotary pump. The CVD growth on silicon was conducted at a pressure of $30 \mathrm{~Pa}$ and a substrate temperature of $350{ }^{\circ} \mathrm{C}$ with a power density of $6.8 \mathrm{Wcm}-2$ (180W per microwave antenna). The plasma density, determined using Langmuir probe measurement, reaches $2 \cdot 1011 \mathrm{~cm}-3$ corresponding to approximately twice the critical density for this excitation frequency $(2.45 \mathrm{GHz})$. The distance between the substrate holder and the applicators was $50 \mathrm{~mm}$. Since the substrate was heated directly by the plasma, no substrate heating was necessary. The dihydrogen and methane gas flows were $47 \mathrm{sccm}$ and $3 \mathrm{sccm}$, respectively, diluted in argon. This gas mixture corresponds to a $97 \% \mathrm{H} 2-$ $3 \% \mathrm{CH} 4$ concentration. It corresponds to the lower left corner in Bachmann diagram for CVD diamond growth and is typically used in the HF-CVD deposition technique. The average growth rate under these conditions was approximately $35 \mathrm{~nm} / \mathrm{h}$. The emission of CVD system was monitored by an Ultima II, Horiba- Scientific, 1m Czerny-Turner spectrometer. The observed spectra included the $\mathrm{CH} A-\mathrm{X},-\mathrm{X}, \mathrm{C}-\mathrm{X}$ molecular bands, the $429.902 \mathrm{~nm}$ line of atomic carbon and various atomic hydrogen lines indicating a high level of dissociation. Raman spectroscopy characterization of the NCD films was performed using a MonoVista CRS+ with a ultra violet (UV) objective $(\times 40) @(325 \mathrm{~nm} ; 20 \mathrm{~mW})$ laser and visible-light lens $(\times 50) @(514 \mathrm{~nm} ; 10 \mathrm{~mW})$ laser. The detector is an InGaAs Andor Camera cooled to $-70{ }^{\circ} \mathrm{C}$. Scanning Electron Microscope (SEM) cross sectional images of the structured Si samples were obtained by cleaving and imaging in a high resolution field emission SEM, model $\mathrm{S} 4800 \mathrm{~N}$ from Hitachi, with a resolution around $2 \mathrm{~nm}$ at 1.5 $\mathrm{kV}$. 


\section{Results}

A silicon chip was cleaved to obtain a cross-section of the structure and to determine the trench geometries by high resolution scanning electron microscopy. Trenches with opening widths of $100,50,20$, and $10 \mu \mathrm{m}$ were crosssectioned. The attained trench depth reduces with decreasing feature width, which is a well-known side-effect [25] due to gas depletion during DRIE. For the Bosch process, this Aspect Ratio Dependent Etch (ARDE) effect becomes prominent as the aperture width decreases to a few microns. The progress of the plasma etch was monitored on a large open area and was stopped when the top-to-bottom offset reached $100 \mu \mathrm{m}$. The resulting trench depths were 100, 98, 80 and $70 \mu \mathrm{m}$,
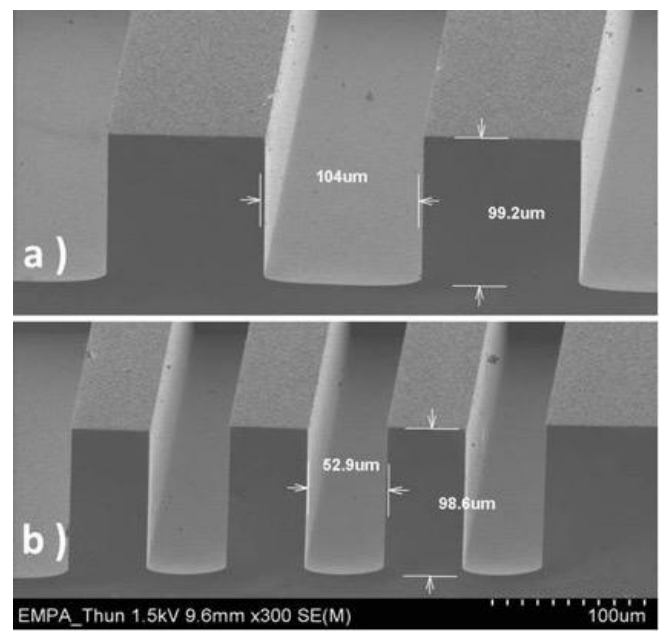

Figure 1: Cross sectional SEM images of trenches with opening widths of a) $100 \mu \mathrm{m}$, b) $50 \mu \mathrm{m}$, imaged at a tilt angle of $70^{\circ}$.

respectively; and the achieved geometries correspond to aspect ratios of 1:1, 1:2, 1:4 and 1:7 (Fig. 1). The trench length in each case was $1 \mathrm{~mm}$. The sidewall scalloping is formed by the alternating etch and passivation steps of the Bosch process and slightly change with trench width due to the ARDE effect. The $10 \mu \mathrm{m}$ wide trench had a scallop height of $610 \mathrm{~nm}$, and an edge to edge width of $190 \mathrm{~nm}$. The values for the $100 \mu \mathrm{m}$ wide trenches were $680 \mathrm{~nm}$ and $230 \mathrm{~nm}$, respectively (Fig. 2).

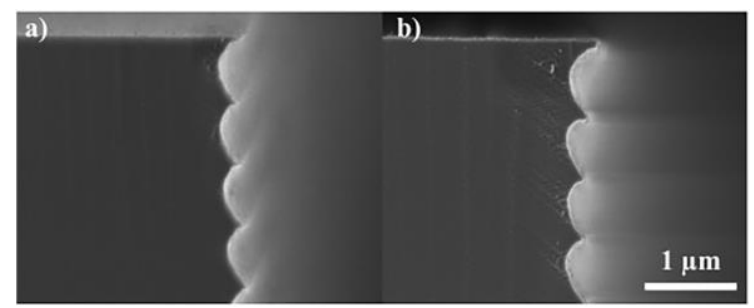

Figure 2: Cross sectional SEM images of scallops: $10 \mu \mathrm{m}$ wide trench on left and $100 \mu \mathrm{m}$ wide trench on right.

\subsection{Seeding Characterization}

The surface coverage resulting from this seeding process was evaluated by treating HR-SEM top-view images (500K magnification) with the "Wand-Auto Measure" Tool of the ImageJ software package. It was found to be of approximately $66 \%$, which then results in a distance between seed agglomerations of around $20 \mathrm{~nm}$. For features with an aspect ratio of 1 , the seed density on the bottom is not significantly different to the top of a feature. However, as the aspect ratio (AR) decreases, the seeding density at the bottom of the trenches also decreases, with the 1:7 $(10 \mu \mathrm{m})$ trench showing very few diamond particles at the bottom of the trench (Fig. $3 a)$. The three geometries with the largest opening widths (100 $\mu \mathrm{m}, 50 \mu \mathrm{m}$, and $20 \mu \mathrm{m}$ ) show a similar seeding density at the bottom of the trench, with only a slightly decreased density in the $20 \mu \mathrm{m}$ geometry. Since these were imaged at a tilt angle of $70^{\circ}$, it is difficult to measure the exact inter-particle spacing for each of the trench geometries. However, as the opening width drops below $20 \mu \mathrm{m}$, noticeably fewer particles are observed on the bottom of the trench with an inter-particle spacing reaching as much as $200 \mathrm{~nm}$. Similar high-resolution images of the seeding density on different sections of the

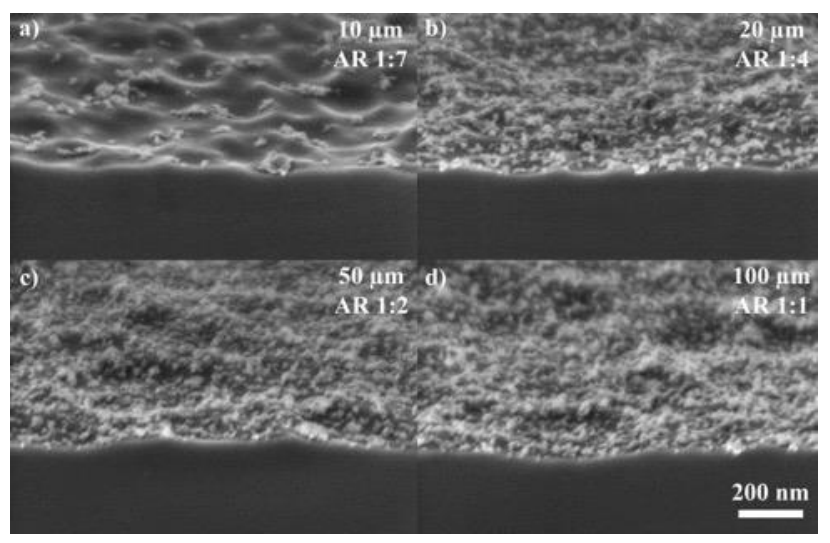

Figure 3. SEM images of bottom seeded surfaces for different trench widths a) $10 \mu \mathrm{m}$ b) $20 \mu \mathrm{m}$ c) $50 \mu \mathrm{m}$ and d) $100 \mu \mathrm{m}$ (imaged at a tilt angle of $70^{\circ}$ ). There is a clear reduction in the seeding density when trenches are thinner than $20 \mu \mathrm{m}$.

sidewalls also showed a dependence on both the depth and AR of the trench. Fig. 4 shows the two extremes in the current study, comparing trenches with an AR of $1: 1$ and 1:7, all imaged at a tilt angle of $70^{\circ}$, at the top, middle and bottom of the trenches. Although the structuring resulting from the DRIE process partially disguises the seeding density, it is apparent that the seeding density on the sidewalls is much lower than the seeding density observed on the surface of the sample. In the middle of the trench, the agglomeration spacing is approximately $45 \mathrm{~nm}$ for the $100 \mu \mathrm{m}$ sample, which is roughly twice what was measured for the top surface. However, for the middle section of the $10 \mu \mathrm{m}$ trench the agglomeration spacing is even greater at about $55 \mathrm{~nm}$. The top section of each trench shows a much higher density when 
compared to the middle, with the $10 \mu \mathrm{m}$ trench showing significantly fewer numbers of particles than both the top surface as well as at the same depth as the $100 \mu \mathrm{m}$ trench. However, the most drastic reduction of seed density is observed at the bottom of the trench, as was mentioned previously.

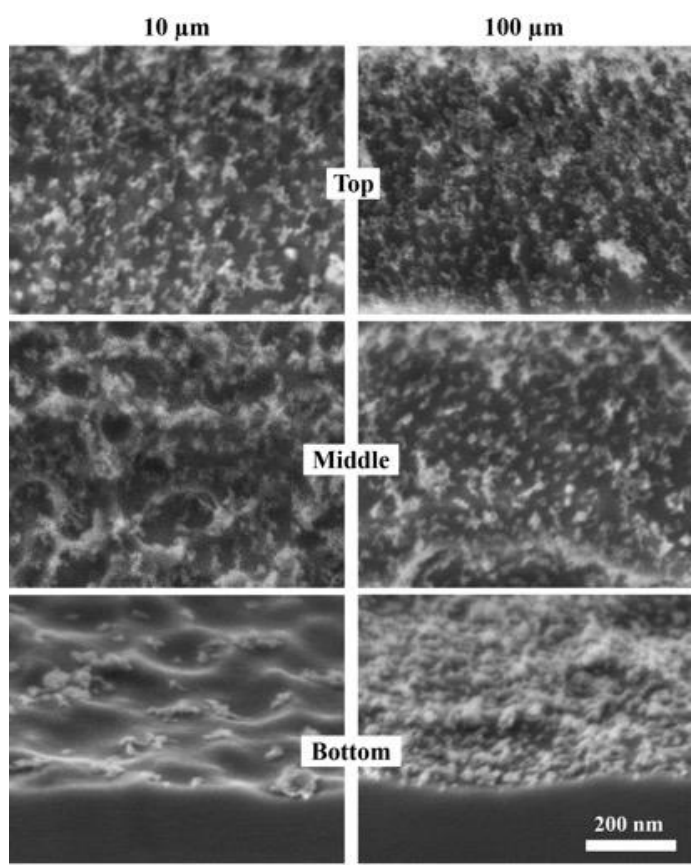

Figure 4. Changing seeding density at the top, middle, and bottom of a $10 \mu \mathrm{m}$ (left) and $100 \mu \mathrm{m}$ (right) trench.

\subsection{Film characterization}

The Raman spectrum of NCD contains typically several components. The $\mathrm{G}$ peak $\left(1600 \mathrm{~cm}^{-1}\right)$ and the $\mathrm{D}$ peak (1350 $\mathrm{cm}^{-1}$ ) are caused by amorphous $\mathrm{sp} 2$ carbon, most likely at the grain boundaries. Several peaks typically associated with NCD are situated at $1460 \mathrm{~cm}^{-1}, 1240-1280 \mathrm{~cm}^{-1}$ and 1170 $\mathrm{cm}^{-1}$, labelled with an S in Fig. 5. The origin of these peaks is still a subject of discussion, but is commonly associated to trans-poly acetylene present on the NCD surface. And finally the sharp peak at $1333 \mathrm{~cm}^{-1}$ caused by the first order Raman response of diamond [18,26-28]. Two laser lines were employed for the Raman measurements, the

$514 \mathrm{~nm}$ (green) line for comparison with results found in the literature and a $325 \mathrm{~nm}$ (UV). Raman scattering of the sp2 components is reduced when excited with the shorter wavelength. At $514 \mathrm{~nm}$, the Raman spectrum has a typical NCD Raman signature [29], where the sharp diamond peak is barely visible. When the shorter wavelength laser source is used the diamond peak becomes clearly distinguished from the background and other carbon contribution, making its identification straight-forward and un-ambiguous. Top-view
SEM images, not shown in this work, were used to estimate the diamond grain size to be in the order of $50 \mathrm{~nm}-100 \mathrm{~nm}$.

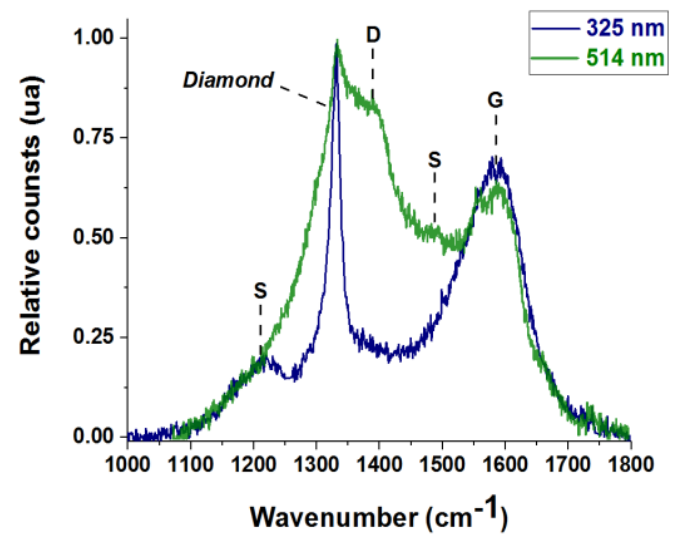

Figure 5: Raman spectra at $325 \mathrm{~nm}$ (blue); $514 \mathrm{~nm}$ (green) for NCD as deposited on 3D Si substrate. D and G indicate broad peaks related to graphitic and amorphous carbon, $S$ to contribution attributed to carbon at the surface of NCD crystals.

\subsection{Film thickness}

Cross-sectional images of the NCD coating on silicon show a compact,

crystalline, smooth layer about $660 \mathrm{~nm}$ thick. As can be seen in Fig. 6, diamond growth was observed inside $100 \mu$ m deep trenches and all along the side-walls of the trench, validating the seeding and CVD plasma parameters used. The top surface of the trench (Fig. 7a) shows a $660 \mathrm{~nm}$ thick and compact NCD layer uniformly grown on the silicon surface. The topcorner (b) is imaged with a lower magnification to present

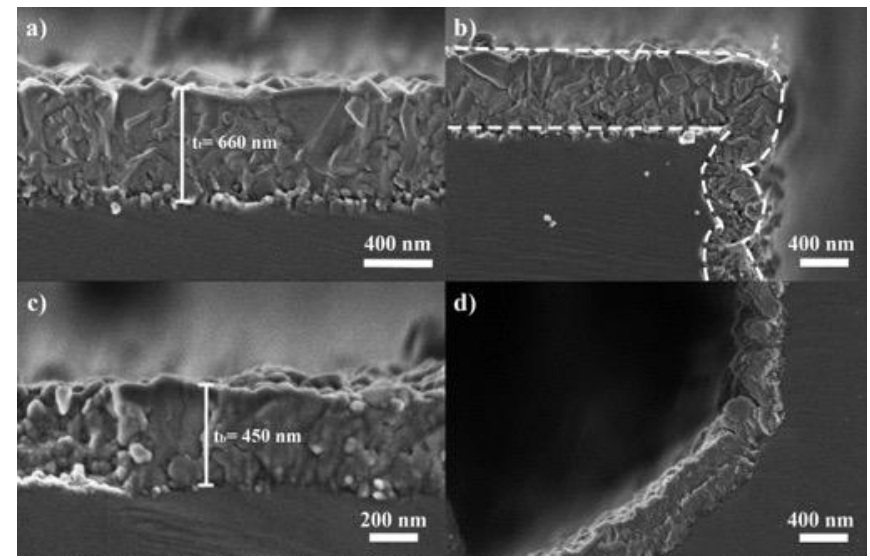

Figure 1: SEM Images of NCD film for $100 \mu \mathrm{m}$ wide trench, a) top, b) top corner, c) bottom, and d) bottom corner

the top surface and vertical wall of the trench. The first scallops which occur during the DRIE silicon etching procedure are visible. These scallops are about $500 \mathrm{~nm}$ in the vertical direction and $100 \mathrm{~nm}$ wide in the horizontal direction. 
They are fully covered with the NCD film and the undulation is visible on the NCD surface, i.e. a high level of conformity is reached.

Fig. 7c shows the NCD growth at the bottom surface of a

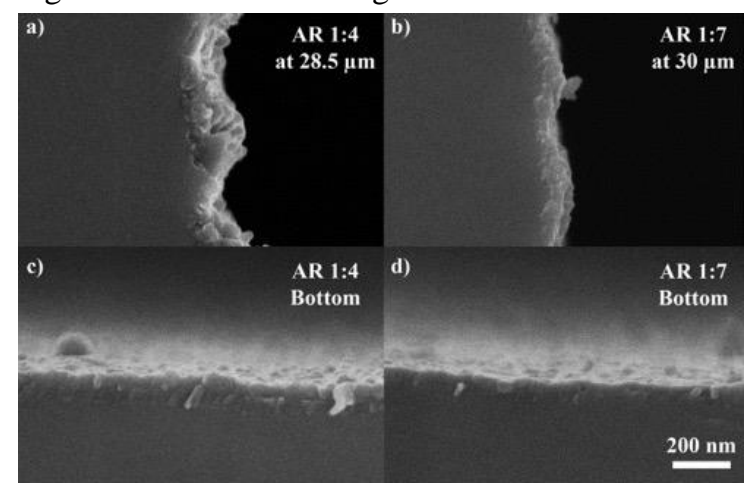

Figure 7: SEM images of NCD growth on high AR trenches. Images were taken on the sidewall of the a) $20 \mu \mathrm{m}$ trench at $\mathbf{2 8 . 5}$ $\mu \mathrm{m}$ and b) $10 \mu \mathrm{m}$ trench at $30 \mu \mathrm{m}$, as well as at the bottom of the c) $20 \mu \mathrm{m} \mathrm{d)} 10 \mu \mathrm{m}$ trenches.

trench. Even at depth of $100 \mu \mathrm{m}$ the bottom is coated with a compact and uniform NCD layer, with a structure very similar to the film grown on the top surface. However, at the bottom of the trench the film only grew to a thickness of $450 \mathrm{~nm}$. Finally, Fig. 7d presents the bottom corner of a trench, where the NCD film follows the silicon surface, remaining dense and homogeneous. The film thickness at the vertical wall is slightly lower compared to the horizontal bottom, as was also observed in the top corner of the trench. The next series of SEM images (Fig. 7), displays the NCD films obtained in trenches with high aspect ratio. No indication of a significant change in film structure, i.e. crystalline structure, can be identified. The film thickness decreases with decreasing trench width, to reach $110 \mathrm{~nm}$ for the bottom $10 \mu \mathrm{m}$ trenches and $150 \mathrm{~nm}$ for the $20 \mu \mathrm{m}$ trenches. Scallops observed on the side wall are fully covered, but a small shadowing effect is observable. Whether this shadowing is a result of a reduction flux density of reactive species generated in the MW plasma or from the initial seeding process is difficult to verify. Table 1 summarizes the film thicknesses measured for the different trench sizes averaging over 7 measurements with a relative uncertainty of approximately $10 \%$.

Table 1: Summary of trench geometries and NCD growth inside the trenches.

\begin{tabular}{|l|c|c|c|c|}
\hline Trench geometry \\
\hline Aspect ratio & $1: 1$ & $1: 2$ & $1: 4$ & $1: 7$ \\
\hline Trench width $(\mathrm{w}) / \mu \mathrm{m}$ & 100 & 50 & 20 & 10 \\
\hline Depth $(\mathrm{L}) / \mu \mathrm{m}$ & 100 & 100 & 80 & 70 \\
\hline Film thickness / nm \\
\hline Top & 660 & 660 & 670 & 660 \\
\hline At 30 $\mu \mathrm{m}$ & 350 & 381 & 249 & 108 \\
\hline Bottom & 450 & 360 & 250 & 110 \\
\hline
\end{tabular}

\section{Discussion}

The complex diamond CVD growth mechanisms involve both creation of sp3 carbon bonds and selective etching of the sp2 carbon by hydrogen. In addition to its role as a selective etchant, hydrogen bombardment creates reactive sites on the diamond surface on which $\mathrm{CH} 3$ radicals can dock [30,31]. Then, the two neighbouring methyl groups can form a sp3 C$\mathrm{C}$ bond and release two hydrogen atoms. These steps, creation of reactive sites on the diamond surface, docking of methyl groups and combination of 2 neighbouring methyl groups are repeated over and over again to form sp3 carbon bonds [32]. However, different or additional growth mechanisms are discussed in the literature

involving not only the methyl radical, $\mathrm{CH} 3$, but also $\mathrm{CH} 2, \mathrm{CH}$ and atomic carbon as source for sp3 carbon addition to the diamond structure [33]. The step coverage (SC) defined as in Eq. (1) can be used to evaluated the $3 \mathrm{D}$ conformity of a deposition process.

$$
S C=\frac{d_{b}}{d_{t}}
$$

where $d_{b}$ and $d_{t}$ are the layer thickness at the bottom of the trench and the top of the substrate, respectively. Many different approaches are possible to describe and model the film growth in 3D structures with high aspect ratios. One such approach, adapted to the low pressure regime used in this study, considers the view factor of surfaces in structures, with high aspect ratios. At a pressure of $30 \mathrm{~Pa}$ the mean free path in the rarefied gas atmosphere is in the millimetre range, significantly above the dimensions of the trenches. Assuming a sticking probability of one, growth along a wall perpendicular to the trench mouth would lead to an estimation of the SC [34]:

$$
S C(z, w)=\left[1-\frac{z}{\left(w^{2}+z^{2}\right)^{\frac{1}{2}}}\right]
$$

where $\mathrm{z}$ is the depth inside the trench, and $\mathrm{w}$ is the width of the trench opening.

Table 2 compares the step coverage on side walls based on the view factor model approximation with the experimental values observed. In particular, for narrow trenches, the calculated film thickness is much lower than what is observed experimentally.

Table 2: Comparison of calculated and experimental step coverage for side walls at approx. $30 \%$ of total trench depth, based on view factor model.

\begin{tabular}{|l|c|c|c|c|}
\hline Trench width $/ \mu \mathrm{m}$ & 100 & 50 & 20 & 10 \\
\hline Depth $/ \mu \mathrm{m}$ & 28 & 28 & 28 & 30 \\
\hline Step Coverage (SC) & 0.73 & 0.51 & 0.19 & 0.05 \\
\hline Calculated & 0.53 & 0.58 & 0.37 & 0.16 \\
\hline Experimental & 0.53
\end{tabular}

Therefore, this specific simple model does not accurately 
describe the growth phenomenon, and another mechanism must exist which includes additional factors like sticking probability. Comparing the trench coverage enhancement, $\mathrm{T}_{\mathrm{e}}$, and surface area enhancement, $S_{e}$, should show the degree of conformity achieved from this process. Te is the ratio of the amount of material deposited in the trench to the amount of material deposited on the cross-sectional surface on the top, while $S_{\mathrm{e}}$ is the ratio of the total trench surface area over the surface area of the trench opening. For a perfectly conformal deposition process $T_{e}$ should be equal to $S_{e}$ [34]. Whereas, if each particle hitting the surface directly contributes to the film growth, i.e. sticking probability equal one, the trench coverage enhancement would be equal to one. In this work, the trench coverage enhancement, $T_{e}$, and surface area enhancement, $S_{e}$, were approximated by:

$$
\begin{gathered}
T_{e}=\frac{2 \cdot d_{s} \cdot L+d_{b} \cdot w}{d_{t} \cdot w} \\
S_{e}=\frac{2 \cdot L+w}{w}
\end{gathered}
$$

Where $L$ and $w$, are the depth and width, the film thickness, $d_{t}$ at the top, $d_{b}$ the bottom and $d_{s}$ at the sidewalls of the trench. The results are summarized in Table 3 .

Table 3: Trench coverage enhancement

\begin{tabular}{|l|r|r|r|r|}
\hline Trench width $/ \mu \mathrm{m}$ & 100 & 50 & 20 & 10 \\
\hline Trench coverage enhancement $\left(T_{e}\right)$ & 1.8 & 2.8 & 3.2 & 2.5 \\
\hline Surface area enhancement $\left(S_{e}\right)$ & 3 & 5 & 9 & 15 \\
\hline
\end{tabular}

The trench coverage enhancement is clearly smaller than the surface area enhancement, indicating the process in not fully conformal. However, a trench coverage enhancement of three indicates that the limiting species entering the trench have a three times higher likelihood to eventually contribute to NCD film growth, compared to those hitting the top surface. The reason for this enhancement is most likely multiple collisions with the trench wall, which relates to a sticking probability for these growth limiting species below one.

Another simple approach to model film growth on structures with high aspect ratios is the microchannel model. It has been described by Yanguas-Gil [34] and references to original work cited. It relies on diffusion of the gaseous compounds rather than a ballistic approach. Although relying on diffusion, it is still applicable for the molecular flow regime in small feature, due to the molecule-wall interaction leading to Knudsen diffusion. This model specifically allows for nonunity sticking probability. If the microchannel model applies, it allows an estimation of the sticking probability. A sticking probability of $\beta=0.1$ seems to best fit the experimental data. However, the agreement between the experimentally observed step coverage and model prediction is still too poor, as shown in Table 4, to trust this value. This values would also be 1000 times higher than the sticking probability of $\mathrm{CH}_{3}$ on a diamond surface as estimated by Schwaederlé et al. [35] using molecular dynamics calculations.

Table 4: Comparison of step coverage based on micro-channel approach to experimental results for the bottom of trenches.

\begin{tabular}{|l|c|c|c|c|}
\hline Trench width $/ \mu \mathrm{m}$ & 100 & 50 & 20 & 10 \\
\hline Step Coverage & 0.47 & 0.54 & 0.35 & 0.13 \\
\hline Micro channel model & 0.68 & 0.55 & 0.22 & 0.16 \\
\hline Experimental
\end{tabular}

The evolution of the step coverage of the NCD layer on deep trenches in Si does not follow either of the two simple models analysed here. The underlying growth mechanism involving at least two different radicals (i.e. atomic hydrogen and $\mathrm{CH}_{\mathrm{x}}$ radical) is likely too complex for a simple model to accurately describe the growth mechanism. In addition, migration of reactive sites on the diamond surface is expected to play a role in NCD growth [35], although this additional mobility is most likely to be limited to displacement on one single crystal, in the $10 \mathrm{~nm}$ range. Furthermore, both of these models assumed no change in seeding density with increasing $\mathrm{AR}$ and depth, which was observed to be a false assumption and further complicates the growth model. More experimental data, i.e. a larger variety of 3D structures, and deposition at different pressures and substrate temperatures, are required to build a base for further detailed analyses of the growth and transport phenomena involved in NCD deposition of high aspect ratio surfaces.

\section{Conclusions}

A novel concept of MEPS microwave plasma reactor has been used for NCD deposition at low temperature. The system uses auto-matched

elementary sources and solid-state microwave generators. Operating without power-dividers and impedance matching, this process offers the possibility of up-scaling in view of industrial application. This new system has been successfully used to produce compact NCD coating on 3D structured silicon substrate, i.e. trenches with aspect ratios up-to seven. The whole process involved the production of the structured silicon wafer using a mask-less etching process, followed by seeding the structured surface with diamond nanoparticles, and finally low temperature deposition of the NCD film. Although the seeding density is clearly dependent on the aspect ratio of the structures, and was very low at the bottom of trench that had an aspect ratio of 1:7, it was sufficient to allow for the growth of the compact NCD layer in these features. The variation of step coverage with the aspect ratio does not follow any of the simple approaches analysed. The NCD growth process, involving several steps and interaction of different radical produced in the MW plasma is obviously too complex to be modelled by the simple approaches used in this study. In addition, the dependence of the growth rate of the seeding density is not yet well understood. The 3D 
conformity of the entire process falls behind full conformity, as achieved by Atomic Layer Deposition (ALD), but is better than the conformity of many Physical Vapor Deposition (PVD) processes. For this NCD MEPS CVD process the amount of diamond grown inside the trenches is approximately 3 times higher than the amount grown on an equivalent crosssectional surface area. Achieving reasonably good 3D conformity for low temperature deposition process presents an important step forward in direction of an industrial application of this technology, for example in the cutting tool, watch, and medical -technology industries. However, there is

room for improvement and further research and development is required prior to a successful industrial application. Directly related to this work, the influence of seeding density on growth rate should be studied in more detail to possibly further reduce the variation of film thickness with changing aspect ratio. Further work on the adhesion of NCD films in particular on substrate materials other than silicon is also Required

\section{Acknowledgements}

This work has been financially supported by the Swiss Federal Commission for Technology and Innovation (CTI) project 16867.2PFNM-NM. The authors would like D. Rats, NeoCoat $\mathrm{SA}, \mathrm{CH}$, for seeding the silicon substrate, financial support, and fruitful discussion. We acknowledge access to and support with UV Raman in the PVLab group at EPFL Neuchatel, $\mathrm{CH}$.

\section{References}

[1] E. Fuentes-Fernandez, J.J. Alcantar-Peña, G. Lee, A. Boulom, H. Phan, B. Smith, T. Nguyen, S. Sahoo, F. Ruiz-Zepeda, M.J. Arellano-Jimenez, P. Gurman, C.A. Martinez-Perez, M.J. Yacaman, R.S. Katiyar, O. Auciello, Synthesis and characterization of microcrystalline diamond to ultrananocrystalline diamond films via Hot Filament Chemical Vapor Deposition for scaling to large area applications, Thin Solid Films 603 (2016) 62-68.

[2] T. Izak, O. Babchenko, M. Varga, S. Potocky, A. Kromka, Low temperature diamond growth by linear antenna plasma CVD over large area, Phys. Status Solidi B 249 (2012) 2600-2603.

[3] K. Tsugawa, M. Ishihara, J. Kim, M. Hasegawa, Y. Koga, Large area and low temperature manodiamond coating by microwave plasma chemical vapor deposition, New Diamond Front. Carbon Technol. 16 (2006) 337-346.

[4] B. Baudrillart, F. Benedic, O. Brinza, T. Bieber, T. Chauveau, J. Achard, A. Gicquel, Microstructure and growth kinetics of nanocrystalline diamond films deposited in large area/low temperature distributed antenna array microwave-plasma reactor, Phys. Status Solidi A 212 (2015) 2611-2615.

[5] O.A. Williams, A. Kriele, J. Hees, M. Wolfer, W. Müller-Sebert, C.E. Nebel, High Young's modulus in ultra thin nanocrystalline diamond, Chem. Phys. Lett. 495 (2010) 84-89.

[6] O.A. Williams, M. Nesladek, M. Daenen, S. Michaelson, A. Hoffman, E. Osawa, K. Haenen, R.B. Jackman, Growth, electronic properties and applications of nanodiamond, Diam. Relat. Mater. 17 (2008) 1080-1088.

[7] M. Possas, L. Rousseau, F. Ghassemi, G. Lissorgues, E. Scorsone, P. Bergonzo, Fabrication and micromechanical characterization of polycrystalline diamond microcantilevers, Microsyst. Technol. 22 (2016) 609-615.

[8] V. Ralchenko, I. Sychov, I. Vlasov, A. Vlasov, V. Konov, A. Khomich, S. Voronina, Quality of diamond wafers grown by microwave plasma CVD effects of gas flow rate, Diam. Relat. Mater. 8 (1999).
[9] S.C. Eaton, M.K. Sunkara, M. Ueno, K.M. Walsh, Modeling the effect of oxygen vapor phase diamond deposition inside microtrenches, Diam. Relat. Mater. 10 (2001) 2212-2219.

[10] V.P. Mammana, R.D. Mansano, P. Verdonck, A. Pavani Filho, M.C. Salvadori, Diamond membranes with controlled porosity, Diam. Relat. Mater. 6 (1997) 1824-1829.

[11] A.V. Sumant, O. Auciello, R.W. Carpick, S. Srinivasan, J.E. Butler, Ultrananocrystalline and nanocrystalline diamond thin films for MEMS/NEMS applications, MRS Bull. 35 (2010) 281-288.

[12] A. Kromka, O. Babchenko, T. Izak, K. Hruska, B. Rezek, Linear antenna microwave plasma CVD deposition of diamond films over large areas, Vacuum 86 (2012) 776-779.

[13] M. Ficek, P. Niedziałkowski, M. Śmietana, M. Koba, S. Drijkoningen, R. Bogdanowicz, W.J. Bock, K. Haenen, Linear antenna microwave chemical vapour deposition of diamond films on long-period fiber gratings for biosensing applications, Opt. Mater. Express 7 (2017) 3952.

[14] H.-A. Mehedi, J. Achard, D. Rats, O. Brinza, A. Tallaire, V. Mille, F. Silva, C. Provent, A. Gicquel, Low temperature and large area deposition of nanocrystalline diamond films with distributed antenna array microwaveplasma reactor, Diam. Relat. Mater. 47 (2014) 58-65.

[15] R.G. Gordon, D. Hausmann, E. Kim, J. Shepard, A kinetic model for step coverage by atomic layer deposition in narrow holes or trenches, Chem. Vap. Depos. 9 (2003) 73-78.

[16] H. Komiyama, Y. Shimogaki, Y. Egashira, Chemical reaction engineering in the design of CVD reactors, Chem. Eng. Sci. 54 (1999) 19411957.

[17] K. Shima, Y. Funato, H. Sugiura, N. Sato, Y. Fukushima, T. Momose, Y. Shimogaki, High-aspect-ratio parallel-plate microchannels applicable to kinetic analysis of chemical vapor deposition, Adv. Mater. Interfaces 3 (2016) 1600254.

[18] A. Floter, G. Schaarschmidt, B. Mainz, S. Laufer, S. Deutschmann, H.J. Hinneberg, Deposition of diamond on patterned silicon substrates, Diam. Relat. Mater. 4 (1995) 930-935.

[19] O.R. Monteiro, H. Liu, Nucleation and growth of CVD diamond films on patterned substrates, Diam. Relat. Mater. 12 (2003) 1357-1361.

[20] V. Ralchenko, I. Vlasov, V. Frolov, D. Sovyk, A. Karabutov, K. Gogolinsky, V. Yunkin, CVD diamond films on surfaces with intricate shape, in: A.A. Voevodin, D.V. Shtansky, E.A. Levashov, J.J. Moore (Eds.) Nanostructured Thin Films and Nanodispersion Strengthened Coatings, Kluwer Academic Publishers, Dordrecht, 2004, pp. 209-220.

[21] D. Rats, C. Provent, Method for a diamond vapor deposition US20160032450A1 - 2016.

[22] A. Grandemange et al., Facility for microwave treatment of a load - US 20140197761A1 - 2014, US 20140197761A1, SAIREM.

[23] B. Baudrillart, F. Bénédic, T. Chauveau, A. Bartholomot, J. Achard, Nanocrystalline diamond films grown at very low substrate temperature using a distributed antenna array microwave process, Diam. Relat. Mater. 75 (2017) $44-51$.

[24] L. Latrasse, M. Radoiu, O. Antonin, T. Nelis, Self-matching plasma sources using $2.45 \mathrm{GHz}$ solid state generators: microwave design and operating performance, J. Microw. Power Electromagn. Energy. 51 (2017) 237-258.

[25] C.M. Huard, Y. Zhang, S. Sriraman, A. Paterson, M.J. Kushner, Role of neutral transport in aspect ratio dependent plasma etching of threedimensional features, J. Vac. Sci. Technol. A 35 (2017) 05C301.

[26] Angel Yanguas-Gil, Growth and Transport in Nanostructured Materials: Reactive

Transport in PVD, CVD and ALD, (2017)

[27] S.S. Baek, B. Choi, Y. Oh, The microstructure of CVD diamond for highdensity thermal inkjet, Microsyst. Technol. 11 (2005) 386-395.

[28] T.V. Kononenko, V.V. Kononenko, V.I. Konov, S.M. Pimenov, S.V. Garnov, A.V. Tishchenko, A.M. Prokhorov, A.V. Khomich, Formation of antireflective surface structures on diamond films by laser patterning, Appl. Phys. A Mater. Sci. Process. 68 (1999) 99-102.

[29] A.C. Ferrari, J. Robertson, Raman spectroscopy of amorphous, nanostructured, diamond-like carbon, and nanodiamond, Philos. Transact. A Math. Phys. Eng. Sci. 362 (2004) 2477-2512.

[30] M.N.R. Ashfold, P.W. May, C.A. Rego, N.M. Everitt, Thin film diamond by chemical vapour deposition methods, Chem. Soc. Rev. (1994) 21-30. 
[31] J.R. Petherbridge, P.W. May, M.N.R. Ashfold, Modeling of the gasphase chemistry in C-H-O gas mixtures for diamond chemical vapor deposition, J. Appl. Phys. 89

(2001) 5219-5223.

[32] R. Beckmann, B. Sobisch, W. Kulisch, On the gas-phase mechanisms in MWCVD and HFCVD diamond deposition, Diam. Relat. Mater. 4 (1995) 256-260.

[33] P.W. May, Y.A. Mankelevich, The mechanism for ultrananocrystalline diamond growth, MRS Proc. 956 (2006) 54.

[34] A. Yanguas-Gil, Growth and Transport in Nanostructured Materials Reactive Transport in PVD, CVD, and ALD, Springer, 2017.

[35] L. Schwaederlé, P. Brault, C. Rond, A. Gicquel, Molecular dynamics calculations of $\mathrm{CH} 3$ sticking coefficient onto diamond surfaces, Plasma Process. Polym. 12 (2015) 764-770. 